\title{
INTEGRATED VIEW OF RAILROAD AND PORT TERMINALS: A STUDY ON THE PORT OF SANTOS, BRAZIL
}

\author{
ULISSES FERNANDES ALVES \\ Production Planning and Control, Rumo Logística, Brazil
}

\begin{abstract}
The Development and Zoning Plan (PDZ) for the port complex of Santos estimates that the share of the railway system in cargo handling will reach about $40 \%$ by 2040 . Thus, it is necessary to implement projects that improve productivity and increase the railway system's capacity; therefore, it may function with such higher demand. To decide and evaluate investments, we developed a simulation model on the Arena ${ }^{\circledR}$ software, considering the randomness and dynamism of the interaction between the railway and the terminals on the right bank of Santos port. To validate our model, we verified the adhesion results for the simulation for the realized values. From this analysis, we obtained $95 \%$ for the number of unloaded cars and $90 \%$ for the cycle time. Then, we evaluated the cycle time gain within two investment scenarios. The first scenario comprises a project that aims to increase the productivity of the discharge of grain hoppers from Terminal G; the second encompasses the construction of viaducts and walkways to remove the speed restrictions of the trains for circulation. In the first scenario, our simulation showed a $\sim 4 \%$ decrease in the wagon cycle on the right bank, which corresponds to a saving of around 1.2 million dollars. For the second scenario, the simulation showed a 7\% decrease in the right bank cycle, thus saving 2.1 million dollars. Therefore, the model presented in this study allows the evaluation of several scenarios and also provides a consistent technical basis for decision making from an integrated view of the railway and port terminals.
\end{abstract}

Keywords: rail yard simulation, discrete events, railway, productivity, Port of Santos.

\section{INTRODUCTION}

The Port of Santos, located in Brazil, is the largest port complex in Latin America and is connected by a wide network of highways, railroads and waterways with six states that concentrate more than $60 \%$ of the Brazilian GDP [1]. There has been a $39 \%$ growth in the millions of tons handled by this port over the last 10 years, as shown in Fig. 1 [2].

Currently, $33 \%$ of the cargo handled at the Port of Santos is transported by railways; this share continues to increase and should reach $40 \%$ by 2040 [3]. For that purpose, several investments must be made in the railway system. However, as the investments are high, it is crucial to carefully study the feasibility of the projects or search for cheaper alternatives to improve the efficiency of the process.

Besides, one of the main concerns that investors have is whether the railway system that currently serves the port can meet the expected demand [4]. Such observation is relevant, as the arrival of cargo at the terminal is crucial to gauge its productivity. If the cargo does not arrive at the port, idleness will increase and, consequently, investments in the terminal will decrease.

Therefore, it is necessary to build accurate models of the railway system to provide more in-depth information on this port's capacity, to examine the gains from the implementation of expansion projects, and to verify the overall effects of individual changes. Given the complexity of the rail processes involved, more appropriate mathematical and computational approaches are required. There are several possibilities and restrictions to the occupation of the railroad, besides the need for an adequate representation of the situations involving human 


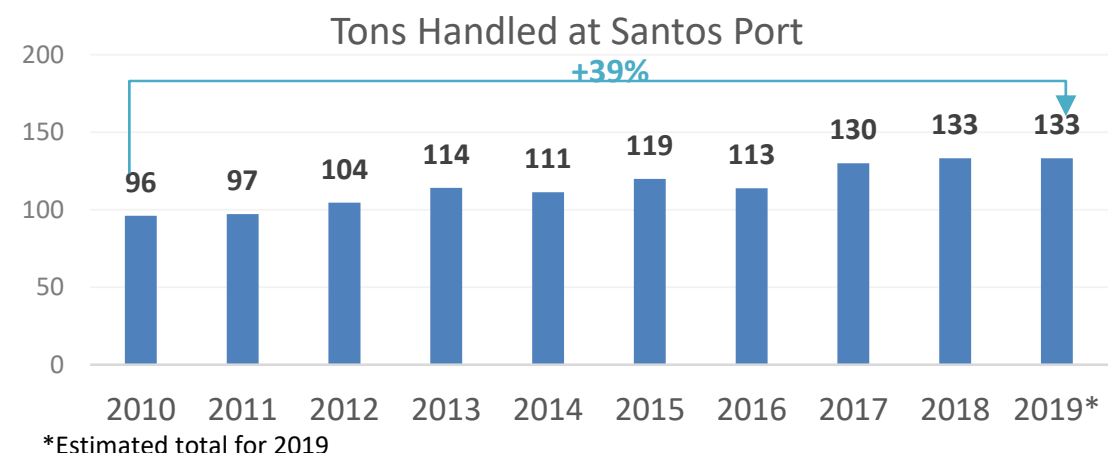

Figure 1: Movement in Santos Port in the period from 2010 to 2019.

decision to move trains. All these factors contribute to the complexity of the models that represent the railway transportation system.

Rumo Logística, a Brazilian logistics company [5], and the consulting firm Paragon [6], made a partnership to develop a model that allows assessing the benefits of projects for the railway systems. This development considered the integration between the railway system and the port terminals on the right bank of the Port of Santos. Importantly, all the needs, restrictions, and challenges mentioned above were also considered. The computational model was implemented using Arena ${ }^{\circledR}$ software developed by the company Rockwell Automation and which allows the simulation of discrete events with resources for statistical analysis, process modelling, animation and results analysis.

\section{LITERATURE REVIEW}

In the literature, railway systems are usually described as employing queuing theories and computational simulations [7]. Petersen [8], [9] used queuing theory to develop a model for yard operations; his model allowed for calculating the probability distribution of the wagon connection times for the various traffic levels. One of the disadvantages of using queuing theory to develop complex models is the need to formulate simplifying hypotheses to obtain an analytical solution - which, in some cases, can distance the results from reality [10].

For the purposes of this study, the computational simulation approach suited our goals more adequately. In this regard, Ramos [11] developed a computational model to analyze the railroad capacity of load processing at the Port of Santos. The author used the Arena ${ }^{\circledR}$ software and evaluated five alternative scenarios that considered both changes in railway operation and the increased demand for trains. According to the author, the limitations of this model are (a) not considering the wagon distribution process for each terminal, (b) disregarding the capacity for wagons at the yards, and (c) not accounting the processing capacity of each terminal separately. We solved these limitations by developing our model which considers the capacity restriction of all resources involved in the railroad operation. This includes the controlled use of each track for the displacement of trains between the yards, the number of locomotives available for maneuver, the management of the movements involved for the distribution of the wagons and the capacity to receive wagons both in yards and at the terminals.

Brito [12] analyzed the implementation proposal of a container regulator terminal in the Cubatão region, located near the Port of Santos, through a computer simulation technique on 
the Arena ${ }^{\circledR}$ software. The author considered the road, water, and rail transport systems to analyze the productivity on the terminal's operation and demand.

Rosa [13] developed a computer simulation model for a railway terminal; the terminal would be used for unloading wagons with agricultural products and loading them with fertilizer. The author generated three scenarios to assess the system behavior and concluded that the simulation model was efficient for carrying out strategic studies while being able to foresee possible difficulties and operational bottlenecks. As potential improvements to the model, the author suggested introducing unexpected interruptions in the operation of any railway line then analyzing their impact in the generation of queues.

Marinov and Viegas [7] proposed a methodology for the simulation, analysis, and evaluation of flat-shunted yard operations. The authors' goal was to divide the yard into areas, so it would be possible to describe and analyze the behavior of each area separately. Thus, it would be equivalent to a queuing network model. A queueing network model consists of interconnected queue systems that influence each other; since it captures the overall impact of railway operations, it is possible to study the processing capacity of the yard.

\section{CASE STUDY}

\subsection{Processes and railway system at the Port of Santos}

The company Portofer (a subsidiary of Rumo Logística) operates and maintains the railway system that serves the terminals at Port of Santos. The companies Rumo, MRS and VLI are three Brazilian railway operators that use Portofer's services to access around $100 \mathrm{~km}$ of railway tracks that extend along the right and left banks of the port. In the right bank under Portofer's control are the rail yards of Santa, Macuco, and Corredor Exportação, which are responsible for a large portion of the maneuvers and the formation and dismemberment of the train compositions. The operational management of the Valongo yard is shared between the companies Portofer and MRS so that there are regions in this yard where each company is responsible for railway control (see division of Valongo's yard in Fig. 2). In the left bank,

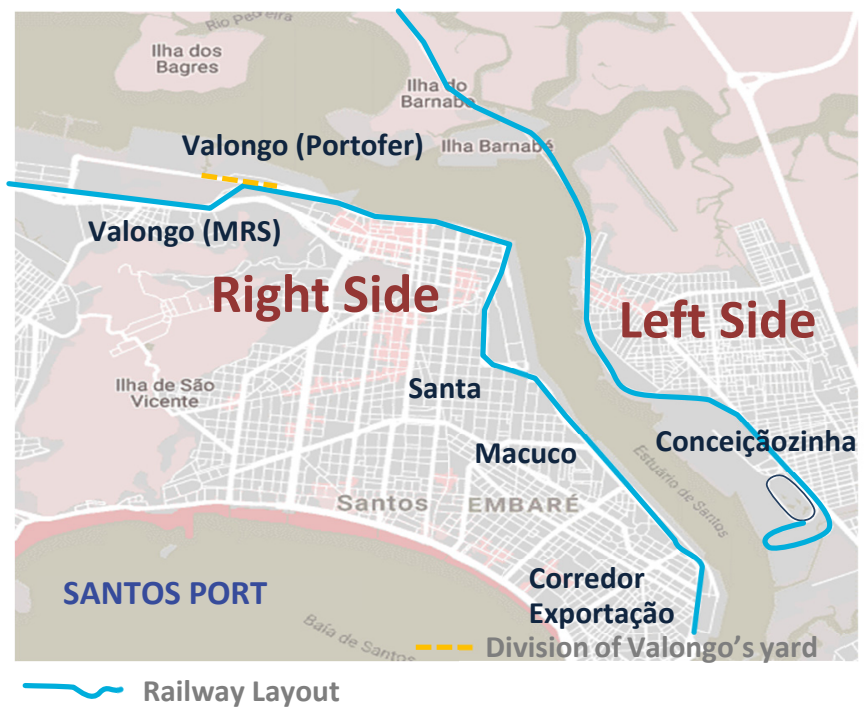

Figure 2: Railway system at the Port of Santos. 
there is only the Conceiçãozinha yard that serves to railway operations. Fig. 2 shows the railway system near the port and the location of the yards on the right and left banks.

In this study, we will only consider the operations on the right bank of the port. The railway operators' compositions start from the MRS rail yard located in Valongo. From this point on, in some cases, train locomotives can be replaced with Portofer's locomotives to transport the wagons to the right parking site. In general, the train composition goes through the processes shown in Fig. 3.

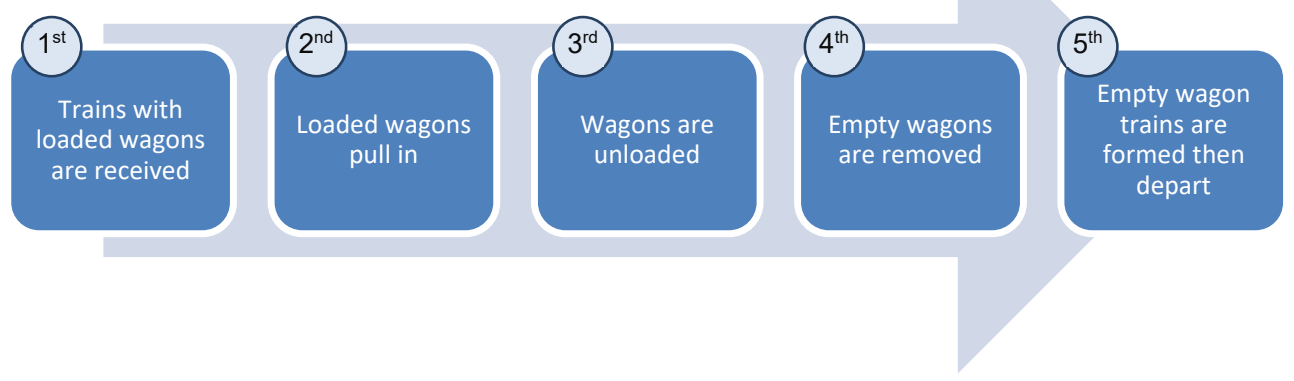

Figure 3: Main rail processes on the right bank.

In the first process, the train is licensed by Portofer's Operational Control Center (CCO) to travel from the Valongo yard to the yard of its destination terminal. In general, once they arrive at their destination yard, the wagons are separated into lots. The lots are moved to unload the wagons according to the availability of the terminal. If the terminal is busy or unavailable, the lots will wait on the parking lines in the yard. The second process starts as soon as the terminal signals the need to receive the wagons. Then, the lots are shunted and transported to the terminal by a locomotive.

In the simulation model, we only included terminals that unload bulk freight wagons (sugar, corn, soy, corn bran, or soy), as listed in Table 1. The other terminals are less representative and were not further analyzed.

Table 1: Right-bank terminals for unloading wagons.

\begin{tabular}{|l|c|}
\hline Yard & Terminals \\
\hline \multirow{4}{*}{ Santa } & A \\
\cline { 2 - 2 } & B \\
\cline { 2 - 2 } & C \\
\cline { 2 - 2 } Corredor Exportação & D \\
\cline { 2 - 2 } & E \\
\cline { 2 - 2 } & F \\
\hline \multirow{3}{*}{} & G \\
\hline
\end{tabular}


After the wagons are shunted, the terminals unload them; the empty wagons are then moved to specific tracks (third process). When there are enough empty wagons, the CCO orders the shunting locomotive to remove the ones close to the terminal and take them to the tracks dedicated to forming empty wagon trains (fourth process). Finally, the fifth process starts when sufficient wagons from the same concessionaire unload the same type of product. This procedure consists of forming the train that will transport these empty wagons. Thus, it is necessary to join the wagons, perform brake tests, and await Portofer CCO's license for the train to move to the Valongo yard. There, the train awaits a license from MRS concessionaire's CCO to depart from the right bank and proceed to a destination outside the Port of Santos.

\subsection{A simulation model for the right bank rail processes}

To build the model, we have considered the steps defined by the simulation methodology presented by Chwif and Medina [14], shown in Fig. 4.

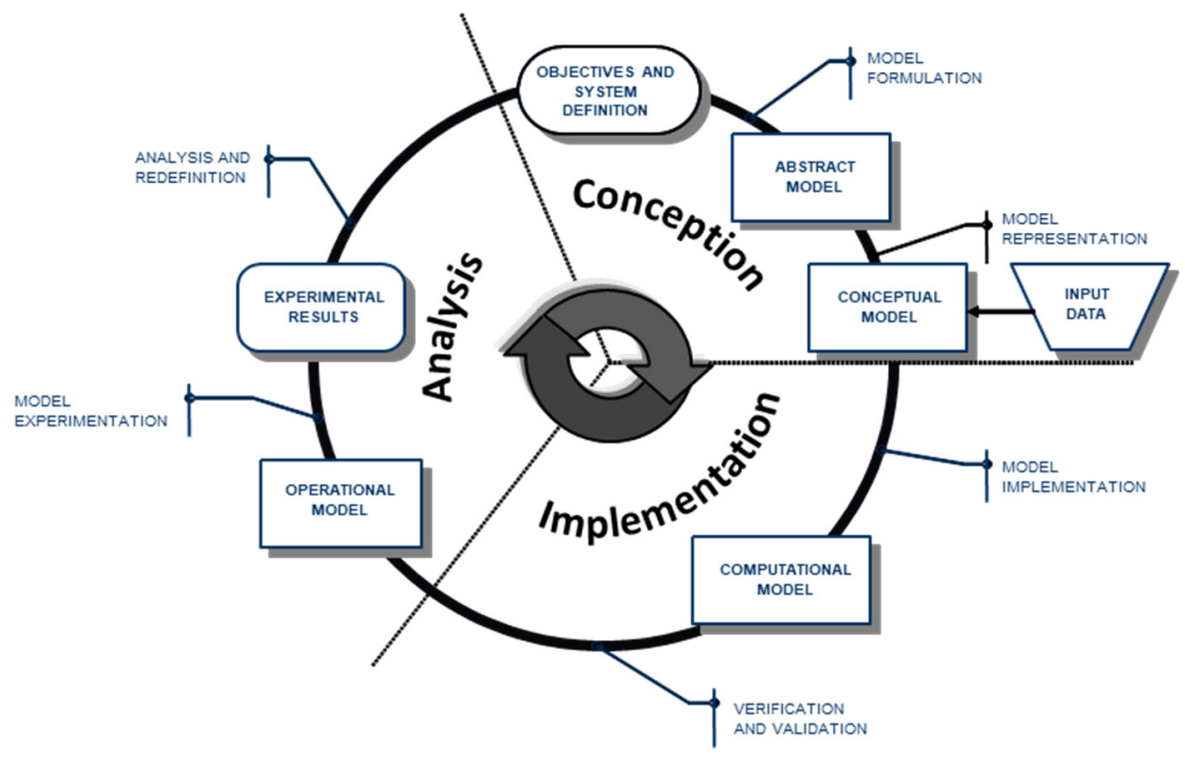

Figure 4: Simulation methodology [14].

The Conception stage consists of defining the objectives of the system and preparing the conceptual model, which consists of documenting tacit knowledge and making it explicit. Implementation activities include the development of the computational model and the correction of possible errors. In the last stage of the cycle, the model becomes operational, as it has passed verification and validation tests and is fit for analyzing the system in question.

During the implementation of the model, the wagons and locomotives were represented as individual entities within the system. The Arena ${ }^{\circledR}$ modeling features allow grouping wagons and locomotives into compositions and ungroup them whenever it is convenient; the individual information of each component is maintained, such as the type of wagon, weight, the concessionaire in charge of the asset, origin, and destination. 
As in the real world, the model's rationale for managing circulation in the railway infrastructure is like the CCO's. This role is crucial to avoid train collisions or even simultaneous use of the same track beyond its capacity. For such purpose, we used a programming approach in Arena ${ }^{\circledR}$ that combines the use of resources and variables. This combination provides flexibility in detailing behaviors and situations present in the railway processes.

To move around the rail yard, one must make a reservation of the railways that will be used. The reservation avoids conflicts with other trains and deadlock situations in which there is a dispute between two entities to access the same route.

For this study, we built and ran the model in the Arena ${ }^{\circledR}$ software version 15.1 Professional. We used ten replications to generate the results, with each replication lasting one month of train operation and circulation on the right bank. The warming time was 24 hours (one day), and the total simulation time equivalent to 7,740 hours (310 days). We chose this configuration to ensure that the variables were able to reach the stationary state.

To validate the model, we evaluated the adhesion of the simulation results to the indicators' real values, according to the eqn (1)

$$
\text { Adhesion }[\%]=\frac{\text { Simulation value }}{\text { Real value }} 100 \text {. }
$$

The adhesion result indicates how close the simulation value is to the realized one. Thus, an adhesion close to $100 \%$ means that the simulation result is close to the realized value. The two indicators evaluated in this study are the number of wagons unloaded at the terminals and the cycle time, which comprises the entire period in which the wagon remained on the right bank. The cycle starts when the wagon enters the Valongo yard and ends when it returns to the entry point in a train with empty cars. In the case of the number of unloaded wagons, adhesion is expected to be equal or less than $100 \%$ because the arrival times of the trains are defined so that the real number of wagons that arrived at the port in a specific month is reached. That is not the case for the cycle time adhesion, as in this case it can assume values above $100 \%$ depending on the dynamic and random interaction of the system.

After validating the model, we assessed the indicators for different processes and productivity scenarios of the terminals. To this purpose, we compared the scenario simulation values with the model simulation results validated for the current processes, as shown in the eqn (2)

$$
\text { Ratio }[\%]=\left(\frac{\text { Simulation value in evaluated scenario }}{\text { Simulation value in current process }(\text { validated case })}-1\right) 100 .
$$

\section{RESULTS AND DISCUSSION}

To validate the simulation model, we compared the real values for July 2019 and the simulation results. Rumo Logística allowed us to publish this paper under the condition of not disclosing operational data. Thus, Table 2 shows only the percentage values of adhesion between the simulation results and the real values.

Table 2: Adhesion of the simulation to the values realized on the right bank in July 2019.

\begin{tabular}{|l|c|}
\hline Indicator & Adhesion (\%) \\
\hline Total number of unloaded wagons & 95 \\
\hline Cycle time & 90 \\
\hline
\end{tabular}


The results in Table 2 show good adhesion to the real number of wagons unloaded on the right bank. Fig. 5 shows the opening of this indicator for each evaluated terminal.

The values of the terminals did not vary significantly. Terminal $\mathrm{D}$ had the lowest adhesion and reached $94 \%$, which is satisfactory. Similarly, the cycle time indicator was also opened for the evaluated terminals, as shown in Fig. 6.

\section{Validation Case: Unloaded Wagons Adhesion [\%]}

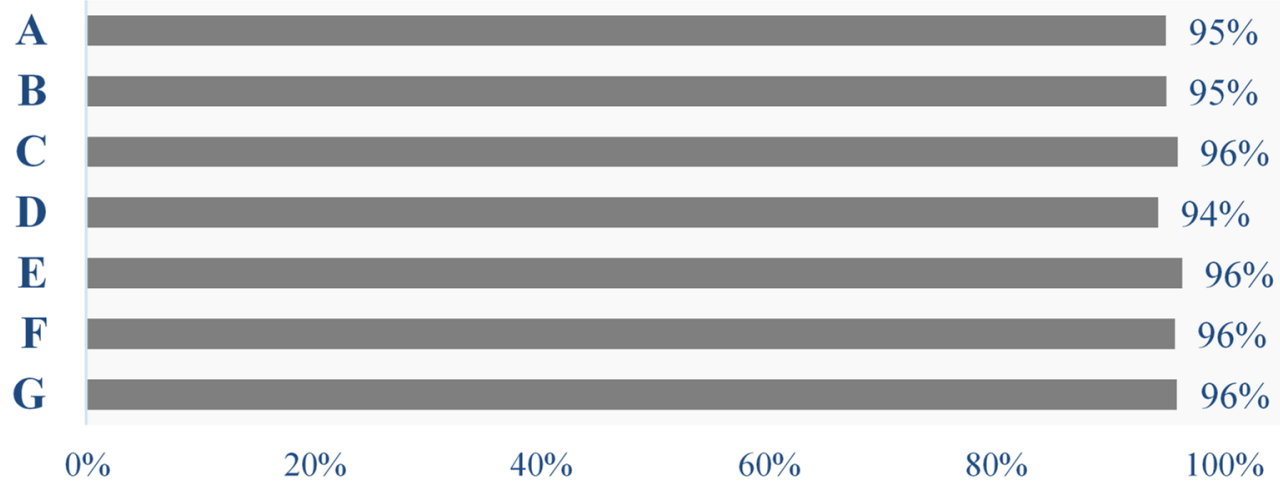

Figure 5: Adhesion percentage of the number of unloaded wagons per terminal.

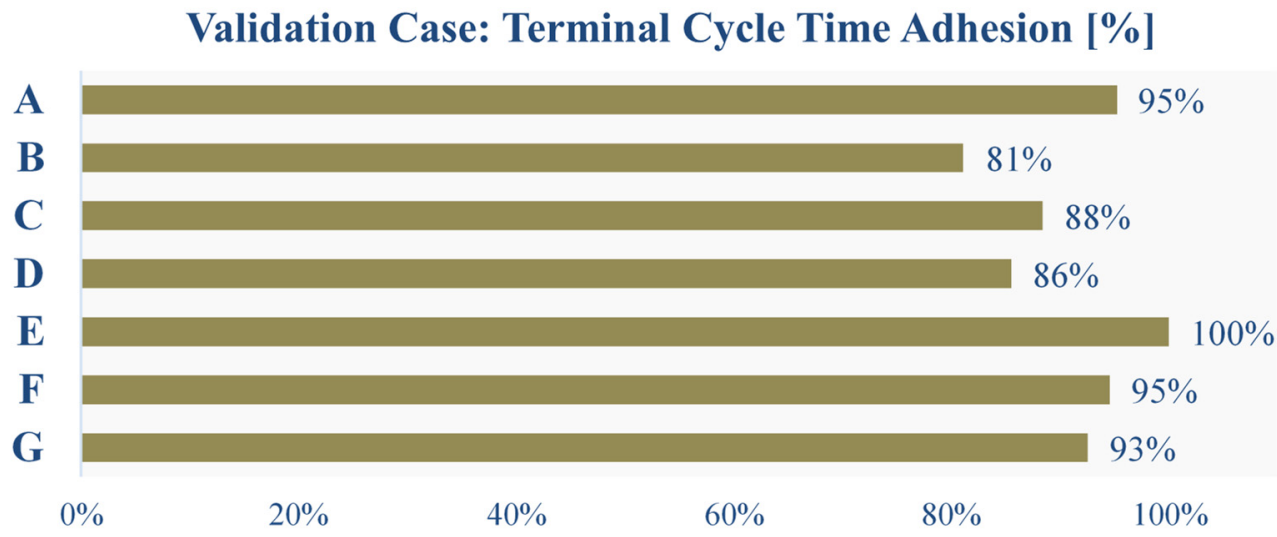

Figure 6: Adhesion percentage of the cycle time per terminal in the simulation of the validation case.

In this case, the adhesion to the cycle time varied more substantially. Low adhesion can be explained by the fact that there are several setbacks during the mentioned processes in Fig. 3, which are either poorly or not recorded at all. Among these setbacks, we highlight the following:

- Terminal maintenance times, when hoppers do not unload, even though wagons are available. 
- Using a wagon type that employs a door for unloading, which is on average $45 \%$ less productive.

- Interference from rain and other elements. In this case, the terminals do not load ships and may not receive wagons for unloading if they are close to their static capacity.

- Interference from trucks during the movement of the wagons towards the hoppers.

- Failures both on the permanent track and on locomotives that delay the moving of wagons.

- Invoicing issues or even mechanical breakdowns in the wagons, which delays their removal.

Nevertheless, the adhesion values for both the number of unloaded cars and cycle time were satisfactory and enough to validate the model. Therefore, this model can be considered operational, which allows us to perform several analyses of the right bank system.

Thus, in Scenario 1, we evaluated the overall gain in cycle time for the entire railway process due to the investment to reduce the unloading time of the wagons at Terminal $\mathrm{G}$ by $36 \%$. For comparison purposes, the departure table of trains in Scenario 1 remained the same as in the validation case; only the unloading time at Terminal $G$ was changed. Fig. 7 shows the percentage ratios between the cycle time results obtained in Scenario 1 and the values of the validated simulation.

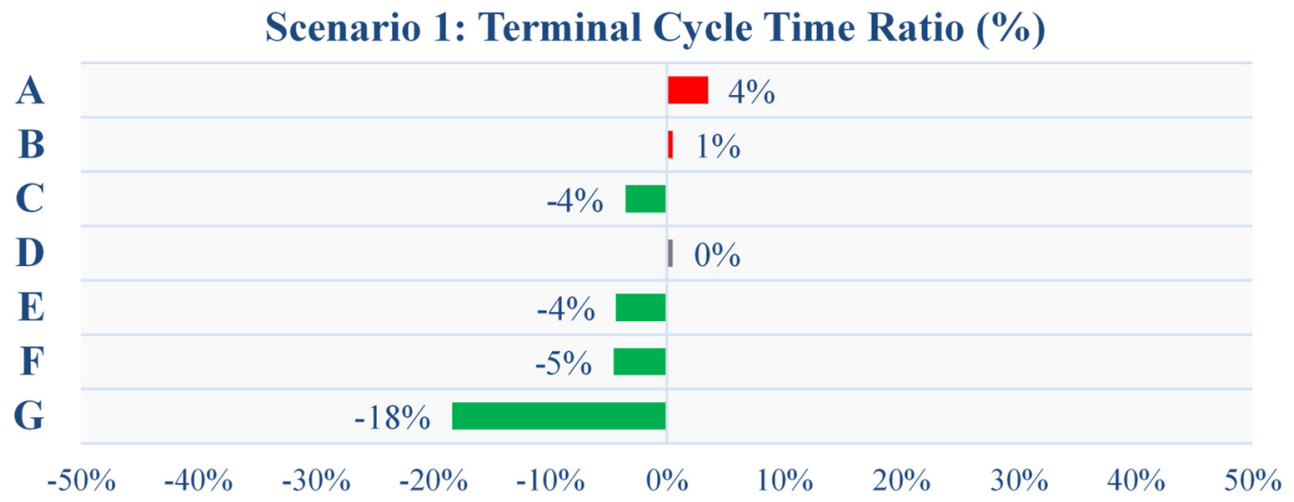

Figure 7: Percentage ratio for cycle time per terminal in the simulation of Scenario 1.

These results show an $18 \%$ decrease in the cycle time of Terminal $\mathrm{G}$ when compared with the validated case. There was no decrease for Terminal $\mathrm{D}$; however, we observed a $1 \%$ increase in the cycle time of Terminal B and 4\% for Terminal A. Thus, it is necessary to evaluate the cycle time stages in order to investigate the reason for such an increase. Fig. 8 shows the corresponding results.

There was an increase in Terminal A train entry and exit times, which suggests that the simulation model prioritizes the flow of trains from other terminals. We can explain such an increase by the fact that the number of cars for Terminal A corresponds to only $6 \%$ of the total unloaded bulk freight wagons on the right bank. Also, there is a restriction rule on the right bank, according to which there can only be one train for each terminal. Thus, the decrease in cycle time in Scenario 1 was due to more available time to unload the wagons, which made these terminals have priority. However, even with the occasional increase in 
Terminal A, the overall cycle time of the right bank reached a $4 \%$ decrease. This value reduced around 17 wagons from the fleet needed to meet the grain flow and resulted in savings of around 1.2 million dollars.

\section{Scenario 1: Terminal A Cycle Time Components Ratio (\%)}

1. Receivement of trains with loaded wagons

2. Loaded wagon pull in

3. Wagon unloading

4. Empty wagon removal

5. Formation and departure of trains with empty wagons

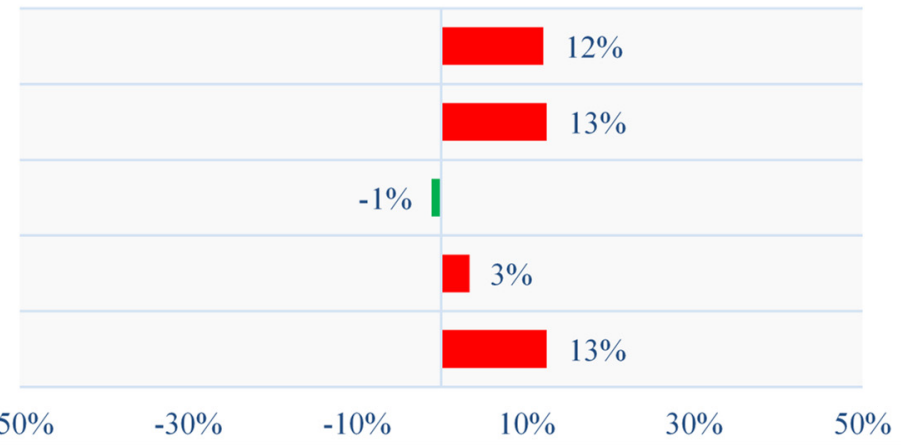

Figure 8: Percentage ratio for the cycle time components of Terminal A in Scenario 1.

Scenario 2 included the evaluation of investment to remove 10 level crossings (PNs) that interfere with train circulation along the right bank. The PNs implies crossing between the railway track and the road for the traffic of people, cars, and trucks. Therefore, for safety reasons, when passing through a $\mathrm{PN}$, the train reduces its speed, meaning an increase of three to 12 minutes in its travel time. Thus, this project consists of establishing viaducts and walkways to eliminate these intersections. Similar to the method applied in Scenario 1, we applied the departure table of trains used in the validation case. Fig. 9 shows the percentage ratios between the cycle time results obtained in Scenario 2 and the validated simulation values.

Investment to remove PNs results in benefit for all evaluated terminals and generates a $7 \%$ decrease in the global cycle time of the right bank, allowing for a decrease of 30 cars in the fleet needed to meet the grain flow and yielding monthly savings of at least 2.1 million dollars.

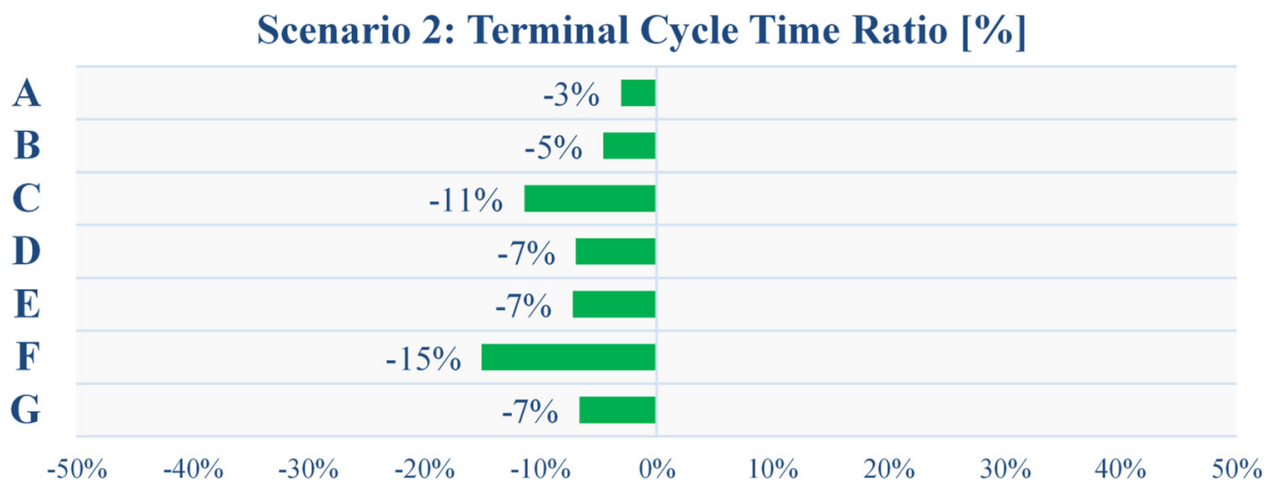

Figure 9: Percentage ratio for the cycle time per terminal in the simulation of Scenario 2. 


\section{CONCLUSIONS}

This study presents the development and application of a model for the integrated simulation between the railway and port terminals located at the right bank of Santos port. This integration allowed us to quantify the effects that would unlikely be evaluated by queuing theory models or other statistical approaches. The validation of the simulation model reached $95 \%$ adhesion for the number of unloaded wagons on the right bank and $90 \%$ for the cycle time. These results are satisfactory, and the lower cycle time adhesion was due to restrictions on reliability or even absence of the times of some rail activities. One of the main challenges and difficulties in developing this simulation model was the definition of the operational rules that allow the entry, exit and circulation of trains in each yard. The solution to this problem came only after several months of interaction with the team responsible for daily operation, which made it possible to understand and record decisions that avoid deadlock or that make the railway operation more efficient.

The evaluations of the projects presented in Scenarios 1 and 2 are critical to direct investments; such assessments allow us to estimate the payback and provide essential information for building a strategic plan. In Scenario 1, the investment in Terminal G only had consequences for the system as a whole. There were benefits to decreasing the cycle time of Terminals $\mathrm{C}, \mathrm{E}$ and $\mathrm{F}$, but the cycle time of Terminal A increased. This increase occurred as a consequence of the smaller number of unloaded cars at Terminal A compared to other terminals. However, we met the entire monthly discharge volume planned for Terminal A. Thus, Scenario 1 benefits most of the rail system.

On the other hand, Scenario 2 benefited all the terminals in the system. These results can stimulate terminal representatives to support this project before the port authorities to accelerate its release. In this sense, the simulation model is beneficial not only from a technical point of view but also in the political sphere, as it provides an argument and logical basis for stimulating concrete actions by stakeholders.

Future studies are required to analyze the railway capacity on the right bank and evaluate other projects, such as the implementation of new railway tracks and the remodeling of the service tracks at the terminals of Corredor Exportação.

\section{ACKNOWLEDGEMENT}

The author thanks Rumo Logística for providing data and for granting the opportunity to develop and present this paper.

\section{REFERENCES}

[1] Porto de Santos, www.portodesantos.com.br/institucional/o-porto-de-santos. Accessed on: 22 Jan. 2020.

[2] Porto de Santos, Mensário Estatístico de Novembro de 2019. intranet.portodesantos.com.br/docs_codesp/doc_codesp_pdf_site.asp?id=128174. Accessed on: 22 Jan. 2020.

[3] Porto de Santos, Plano de Desenvolvimento e Zoneamento - PDZ. www.portodesantos.com.br/wp_porto/wp-content/uploads/2020/02/apresentacaocoletiva-pdz.pdf. Accessed on: 1 Mar. 2020.

[4] Agência Infra, www.agenciainfra.com/blog/preocupacao-com-acesso-ferroviario-edestaque-em-audiencia-publica-no-porto-de-santos/. Accessed on: 22 Jan. 2020.

[5] Rumo Logística, www.rumolog.com. Accessed on: 1 Mar. 2020.

[6] Paragon Consulting, www.paragon.com.br. Accessed on: 1 Mar. 2020. 
[7] Marinov, M. \& Viegas, J., A simulation modelling methodology for evaluating flatshunted yard operations. Simulation Modelling Practice and Theory, 17(6), pp. 11061129, 2009.

[8] Petersen, E.R., Railyard modeling: Part I. Prediction of put-through time. Transportation Science, 11(1), pp. 37-49, 1977.

[9] Petersen, E.R., Railyard modeling: Part II. The effect of yard facilities on congestion. Transportation Science, 11(1), pp. 50-59, 1977.

[10] Freitas Filho, P.J., Introdução à modelagem e simulação de sistemas: com aplicações em Arena ${ }^{\circledR}$, Visual Books: Florianópolis, p. 59, 2008.

[11] Ramos, G.M., Análise prospectiva da capacidade de processamento de cargas pela ferrovia no porto de Santos. Master's dissertation, University of São Paulo, 2003. DOI: 10.11606/D.18.2003.tde-11102003-153159.

[12] Brito, T.B., Modelagem e simulação de um terminal regulador de contêineres. Graduation work, Polytechnic School of the University of São Paulo, 2008.

[13] Rosa, R.A, Uma proposta de um modelo matemático para a programação das atividades de um terminal ferroviário de carga. XXI Congresso de Ensino e Pesquisa em Transportes (ANPET), Rio de Janeiro, 2007.

[14] Chwif, L. \& Medina, A., Modelagem e simulação de eventos discretos: Teoria e aplicações, Elsevier Brasil: São Paulo, 2015. 